\title{
Comparison of Clinical Outcomes of Gastrojejunal Bypass and Gastrectomy in Patients With Metastatic Gastric Cancer
}

\author{
DAIKI MATSUBARA, HIROTAKA KONISHI, TAKESHI KUBOTA, TOSHIYUKI KOSUGA, KATSUTOSHI SHODA, \\ ATSUSHI SHIOZAKI, HITOSHI FUJIWARA, KAZUMA OKAMOTO and EIGO OTSUJI
}

Division of Digestive Surgery, Department of Surgery, Kyoto Prefectural University of Medicine, Kyoto, Japan

\begin{abstract}
Background/Aim: Surgical therapy for stage IV gastric cancer patients is still debatable. The clinical outcomes were compared between gastrojejunal bypass and gastrectomy for metastatic gastric cancer patients. Patients and Methods: A total of 110 patients with metastatic gastric cancer who underwent surgery were retrospectively analyzed. Twenty-nine patients underwent gastrojejunal bypass (group B) and 81 underwent gastrectomy (group G). Results: There was no significant difference in the 3-year overall survival between Group $G$ patients with partial gastrectomy and total gastrectomy. However, patients in group $G$ had a significantly better prognosis compared to patients in group $B(p=0.01$ and 0.03 , respectively). The prognosis of patients with postoperative chemotherapy was significantly better in group $G$ compared to group $B$ $(p=0.03)$, whereas it was not significantly different for the patients without postoperative chemotherapy $(p=0.24)$. Conclusion: Gastrectomy in patients with metastatic gastric cancer may improve survival when combined with postoperative chemotherapy.
\end{abstract}

Gastric cancer is the fifth most common cancer and the third leading cause of cancer-related mortality worldwide (1). Among gastric cancers, metastatic gastric cancer has an especially poor prognosis. Although the prognosis of stage IV gastric cancer has been recently improved as a result of new chemotherapeutic and molecular-targeting drugs, the median survival in patients with metastatic gastric cancer is only about 10 months $(2,3)$.

Correspondence to: Hirotaka Konishi, Division of Digestive Surgery, Department of Surgery, Kyoto Prefectural University of Medicine, 465 Kajii-cho, Kawaramachihirokoji, Kamigyo-ku, Kyoto 602-8566, Japan. Tel: +81 752515527, Fax: +81 752515522, e-mail: h-koni7@koto.kpu-m.ac.jp

Key Words: Metastatic gastric cancer, palliative gastrectomy, gastrojejunal bypass, REGATTA trial.
Chemotherapy is the standard of care for patients with stage IV gastric cancer, as stated in the Japanese treatment guidelines (4), so these patients are not eligible for radical resection. However, patients with stage IV gastric cancer sometimes undergo surgery, including a gastrojejunal bypass or gastrectomy, to relieve cancer-related symptoms, such as tumor bleeding, obstruction, or perforation. Some studies have indicated that palliative gastrectomy not only relieves cancer-related symptoms but also improves the prognosis. However, other studies have demonstrated that the outcomes of surgical resection in stage IV gastric cancer are poor (5-9).

Recently, investigators of the REGATTA trial concluded that gastrectomy followed by chemotherapy did not impart any benefits to overall survival compared to chemotherapy alone in advanced gastric cancer patients with a single noncurative factor (10). However, this study was a well-planned randomized clinical study for patients with or without surgery, and the patients did not have any symptoms, such as a bleeding or poor oral intake. Besides, the indication or significance of gastrojejunal bypass remains unclear, and surgical therapy for metastatic gastric cancer is still debatable.

The aim of this study was to investigate whether gastrojejunal bypass or palliative gastrectomy contributed to the short-term outcomes and prognoses of patients with metastatic gastric cancer.

\section{Patients and Methods}

Patients. A total of 110 patients with metastatic gastric cancer who underwent surgery at Kyoto Prefectural University of Medicine between 2004 and 2015 were retrospectively registered in this study. Of 110 patients, 29 patients underwent gastrojejunal bypass (group B) and 81 patients underwent gastrectomy (group G). The clinical data from the medical records and database of our institution were reviewed. Preoperative diagnoses of gastric adenocarcinoma were confirmed by endoscopy followed by biopsy. Metastatic disease was defined from the preoperative findings on computed tomography and positron emission tomography, or from the intraoperative findings. The clinical stage was determined based on the Japanese Classification of Gastric Carcinoma 3rd edition (11). We evaluated 
Table I. Comparison of clinicopathological factors.

\begin{tabular}{|c|c|c|c|c|}
\hline Variables & $\mathrm{n}=110$ & $\begin{array}{c}\text { Bypass } \\
\mathrm{n}=29\end{array}$ & $\begin{array}{c}\text { Gastrectomy } \\
n=81\end{array}$ & $p$-Value ${ }^{\mathrm{c}}$ \\
\hline Age, years & $67.4 \pm 10.7$ & $70.3 \pm 7.6$ & $66.4 \pm 11.4$ & 0.13 \\
\hline \multicolumn{5}{|l|}{ Gender } \\
\hline Female & 38 & $11(38 \%)$ & $27(33 \%)$ & \multirow[t]{2}{*}{0.66} \\
\hline Male & 72 & $18(62 \%)$ & $54(67 \%)$ & \\
\hline \multicolumn{5}{|c|}{ The number of non-curative factor } \\
\hline 1 & 77 & $13(45 \%)$ & $64(79 \%)$ & \multirow[t]{2}{*}{$<0.001$} \\
\hline$\geq 2$ & 33 & $16(55 \%)$ & $17(21 \%)$ & \\
\hline \multicolumn{5}{|l|}{ Preoperative symptoms } \\
\hline Cancer bleeding & 26 & 8 & 18 & 0.56 \\
\hline Stenosis & 37 & 21 & 16 & $<0.001$ \\
\hline \multicolumn{5}{|c|}{ Preoperative poor oral intake } \\
\hline Presence & 43 & $19(66 \%)$ & $24(30 \%)$ & \multirow[t]{2}{*}{$<0.001$} \\
\hline Absence & 67 & $10(34 \%)$ & $57(70 \%)$ & \\
\hline \multicolumn{5}{|l|}{ Preoperative chemotherapy } \\
\hline Presence & 29 & $6(21 \%)$ & $23(28 \%)$ & \multirow[t]{2}{*}{0.42} \\
\hline Absence & 81 & $23(79 \%)$ & $58(74 \%)$ & \\
\hline $\mathrm{Hb}, \mathrm{g} / \mathrm{dL}$ & $10.9 \pm 2.5$ & $10.4 \pm 2.6$ & $11.0 \pm 2.4$ & 0.25 \\
\hline $\mathrm{Alb}, \mathrm{g} / \mathrm{dL}$ & $3.77 \pm 0.53$ & $3.58 \pm 0.53$ & $3.84 \pm 0.05$ & 0.02 \\
\hline $\mathrm{CEA}, \mathrm{ng} / \mathrm{ml}$ & $12.1 \pm 54.1$ & $6.3 \pm 0.8$ & $14.2 \pm 63.1$ & 0.13 \\
\hline CA19-9, U/ml & $90.9 \pm 596.5$ & $15.9 \pm 3.06$ & $118.4 \pm 696$ & 0.52 \\
\hline \multicolumn{5}{|l|}{ cT stage ${ }^{\mathrm{a}}$} \\
\hline $\mathrm{T} 1,2$ & 13 & $1(3 \%)$ & $12(15 \%)$ & \multirow[t]{2}{*}{0.10} \\
\hline $\mathrm{T} 3,4$ & 97 & $28(97 \%)$ & $69(85 \%)$ & \\
\hline \multicolumn{5}{|l|}{ cN stage ${ }^{a}$} \\
\hline No, 1 & 29 & $9(31 \%)$ & $20(25 \%)$ & \multirow[t]{2}{*}{0.51} \\
\hline $\mathrm{N} 2,3$ & 81 & $20(69 \%)$ & $61(75 \%)$ & \\
\hline \multicolumn{5}{|l|}{ Location } \\
\hline ML & 67 & $27(93 \%)$ & $40(49 \%)$ & \multirow[t]{2}{*}{$<0.001$} \\
\hline $\mathrm{U}$ & 43 & $2(7 \%)$ & $41(51 \%)$ & \\
\hline \multicolumn{5}{|l|}{ Histological type } \\
\hline Undifferentiated & 75 & $19(73 \%)$ & $56(69 \%)$ & \multirow[t]{2}{*}{0.70} \\
\hline Differentiated & 35 & $10(27 \%)$ & $25(31 \%)$ & \\
\hline \multicolumn{5}{|l|}{ Invasion to other organ } \\
\hline Presence & 35 & $18(62 \%)$ & $17(21 \%)$ & \multirow[t]{2}{*}{$<0.001$} \\
\hline Absence & 75 & $11(38 \%)$ & $64(79 \%)$ & \\
\hline Operative Blood loss, ml & $329.5 \pm 331.8$ & $89.2 \pm 177.6$ & $421.2 \pm 331.8$ & $<0.001$ \\
\hline Operative time, $\min$ & $239.9 \pm 109.3$ & $137.0 \pm 41.0$ & $278.6 \pm 101.6$ & $<0.001$ \\
\hline \multicolumn{5}{|l|}{ Postoperative complication ${ }^{b}$} \\
\hline Presence & 22 & $4(12 \%)$ & $18(22 \%)$ & \multirow[t]{6}{*}{0.33} \\
\hline Absence & 88 & $25(88 \%)$ & $63(78 \%)$ & \\
\hline Grade II & & $2(6 \%)$ & $11(14 \%)$ & \\
\hline Grade IIIa & & $2(6 \%)$ & $5(6 \%)$ & \\
\hline Grade IIIb & & $0(0 \%)$ & $1(1 \%)$ & \\
\hline Grade IVa & & $0(0 \%)$ & $1(1 \%)$ & \\
\hline Hospital stay, days & $25.4 \pm 18.7$ & $22.4 \pm 21.9$ & $26.5 \pm 17.4$ & 0.02 \\
\hline \multicolumn{5}{|l|}{ Postoperative chemotherapy } \\
\hline Presence & 83 & $19(70 \%)$ & $64(79 \%)$ & 0.15 \\
\hline Absence & 27 & $10(30 \%)$ & $17(21 \%)$ & \\
\hline
\end{tabular}

aAccording to the Japanese Classification of Gastric Carcinoma 3rd edition; ${ }^{b}$ Grade II or above according to the Clavien-Dindo classification; ${ }^{c} p$-Values are from Chi-squared test or Mann-Whitney $U$-test. Hb: Hemoglobin; Alb: albumin; CEA: carcinoembryonic antigen; CA19-9: carbohydrate antigen199; cT: clinical T; cN: clinical N; ML: middle or lower third of stomach; U: upper third of stomach.

the grade of postoperative complications using the Clavien-Dindo classification. Patients with grade II or greater complications were considered complication-positive $(12,13)$.

The present study was conducted in accordance with the principles of the Declaration of Helsinki (14), and written informed consent for the treatments was obtained from all patients. Ethical approval from the Facility of Science Committee at the Kyoto Prefectural University of Medicine was not required, as the present study was a retrospective observational study without interventions provided for the therapeutic purposes. 
Table II. Details of 1st line postoperative chemotherapy.

\begin{tabular}{lccc}
\hline Chemotherapy regimen & $\begin{array}{c}\text { Bypass } \\
\mathrm{n}=29\end{array}$ & $\begin{array}{c}\text { Gastrectomy } \\
\mathrm{n}=81\end{array}$ & $\begin{array}{c}\text { Total } \\
\mathrm{n}=110\end{array}$ \\
\hline No chemotherapy & 10 & 17 & 27 \\
TS-1 based regimen & 15 & 46 & 61 \\
TS-1 alone & $(5)$ & $(19)$ & $(24)$ \\
TS-1+CDDP & $(7)$ & $(17)$ & $(24)$ \\
Others & $(3)$ & $(10)$ & $(13)$ \\
PTX based regimen & 3 & 9 & 12 \\
CPT-11 based regimen & 1 & 3 & 4 \\
Others & 0 & 6 & 6 \\
\hline
\end{tabular}

TS-1: Tegafur/Gimeracil/Oteracil; CDDP: cis-diamminedichloroplatinum; PTX: paclitaxel; CPT-11: camptothecin-11.

Surgical therapy. In group $\mathrm{G}$, total or subtotal gastrectomy was performed according to the location of the primary tumor. The Billroth I, Roux-en-Y, or esophagogastric anastomosis was performed according to the types of gastrectomy. In group B, the gastrojejunostomy was placed in the middle third of the greater curvature of the stomach using a linear stapler by either a laparoscopic approach or open laparotomy.

Postoperative chemotherapy. The chemotherapeutic regimens were selected based on the judgment of an attending physician and the status of the patient. The main regimens included Tegafur/ Gimeracil/Oteracil (TS-1), Paclitaxel, or Camptothecin-11, and were administered according to the standard protocol.

Statistical analysis. The categorical variables in the two groups were compared using the Chi-square test. Continuous variables were summarized by mean $( \pm \mathrm{SD})$, and the groups were compared using the Mann-Whitney $U$-test. Curves for overall survival were derived using the Kaplan-Meier method and were compared using the Logrank test. A multivariate survival analysis was performed using Cox's proportional hazard regression model. A $p$-value $<0.05$ was considered significant. JMP 10.0 statistical software for Macintosh (SAS Institute, Cary, NC, USA) was used for all analyses.

\section{Results}

Patient characteristics. The clinico-pathological characteristics of the patients are shown in Table I. Multisite distant metastasis, stenosis, and poor preoperative oral intake were significantly frequent in group B. The preoperative serum albumin levels in group B was significantly lower compared to those in group $\mathrm{G}(p=0.02)$, whereas the preoperative levels of hemoglobin and tumor markers were similar between the two groups. No significant differences were observed regarding clinical $\mathrm{T}$ or $\mathrm{N}$ stages, histological types, or the frequency of postoperative chemotherapy between the two groups. The location of the primary lesion in the middle and lower thirds of the stomach, and tumor invasion into the surrounding organs were significantly frequent in group B $(p<0.001)$.
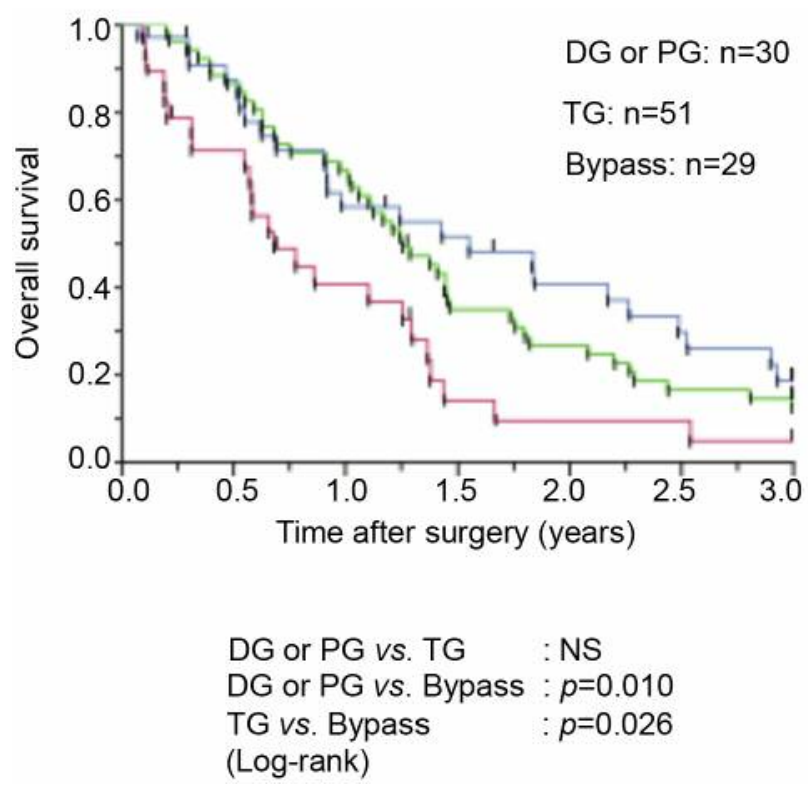

Figure 1. Survival analysis according to the type of surgery. Overall survival using the Kaplan-Meier method is shown for patients who underwent total gastrectomy, distal and proximal gastrectomy, or gastrojejunal bypass. DG: Distal gastrectomy; $P G$ : proximal gastrectomy; TG: total gastrectomy.

Complications and postoperative chemotherapy. The grades of complications are shown in Table I. Four patients (12\%) in group B, and 18 patients $(22 \%)$ in group $\mathrm{G}$ had postoperative complications of grade 2 or higher $(p=0.33)$. Postoperative hospital stays were significantly longer in group $\mathrm{G}$ compared to group B [21 days (10-101) versus 15 days (7-117), $p=0.02]$.

The details of 1st-line postoperative chemotherapy in both groups are shown in Table II. Nineteen patients (70\%) in group $\mathrm{B}$ and 64 patients $(79 \%)$ in group $\mathrm{G}$ received any regimens of chemotherapy $(p=0.14)$. TS-1-based chemotherapy was frequently given in both groups $[15$ patients $(51 \%)$ in group B, and 46 patients $(56 \%)$ in group $\mathrm{G}]$.

Survival analyses. The prognosis was analyzed according to the types of surgery (Figure 1). Although there was no significant difference in the 3-year overall survival (OS) of patients who underwent distal (DG) or proximal (PG) gastrectomy $(16.4 \%)$ and total gastrectomy (TG) $(10.4 \%)$ in group $\mathrm{G}$, the patients with either type of gastrectomy showed significantly better 3-year OS compared to the group B patients $(4.63 \% ; p=0.01$ and $p=0.03$, respectively).

Table III shows the correlation between survival and the clinico-pathological factors for the 110 patients. Older age ( $\geq 70$ years, $p=0.004)$, presence of poor preoperative oral intake $(p=0.01)$, tumor invasion into other organs $(p=0.01)$, clinical N2-3 $(p=0.03)$, absence of postoperative chemotherapy 
Table III. Univariate and multivariate analyses of prognostic factors.

\begin{tabular}{|c|c|c|c|c|c|c|}
\hline \multirow[t]{2}{*}{ Variables } & \multicolumn{3}{|c|}{ Univariate } & \multicolumn{3}{|c|}{ Multivariate } \\
\hline & $\mathrm{n}=110$ & 3 -years OS (\%) & $p$-Value ${ }^{c}$ & HR & $95 \% \mathrm{CI}$ & $p$-Value \\
\hline \multicolumn{7}{|l|}{ Age, years } \\
\hline$\geq 70$ & 51 & 5.43 & 0.004 & 1.93 & $1.15-3.22$ & 0.01 \\
\hline$<70$ & 59 & 14.7 & & & & \\
\hline \multicolumn{7}{|l|}{ Gender } \\
\hline Female & 38 & 8.69 & 0.98 & & & \\
\hline Male & 72 & 11.6 & & & & \\
\hline \multicolumn{7}{|l|}{ Location } \\
\hline ML & 67 & 10.7 & 0.88 & & & \\
\hline $\mathrm{U}$ & 43 & 10.5 & & & & \\
\hline \multicolumn{7}{|c|}{ Preoperative poor oral intake } \\
\hline Presence & 43 & 6.03 & 0.01 & 1.17 & $0.69-1.95$ & 0.55 \\
\hline Absence & 67 & 13.4 & & & & \\
\hline \multicolumn{7}{|c|}{ The number of non-curative factor } \\
\hline 1 & 77 & 13.3 & 0.07 & & & \\
\hline$\geq 2$ & 33 & 3.85 & & & & \\
\hline \multicolumn{7}{|l|}{ cT stage ${ }^{a}$} \\
\hline $\mathrm{T} 3,4$ & 97 & 9.43 & 0.27 & & & \\
\hline $\mathrm{T} 1,2$ & 13 & 19.9 & & & & \\
\hline \multicolumn{7}{|c|}{ Invasion to other organ } \\
\hline Presence & 35 & 3.30 & 0.01 & - & - & - \\
\hline Absence & 75 & 14.1 & & & & \\
\hline \multicolumn{7}{|l|}{$\mathrm{cN}$ stage $^{\mathrm{a}}$} \\
\hline $\mathrm{N} 2,3$ & 81 & 6.88 & 0.03 & 1.80 & $1.04-3.26$ & 0.03 \\
\hline No, 1 & 29 & 22.5 & & & & \\
\hline \multicolumn{7}{|c|}{ Histopathological type } \\
\hline Undifferentiated & 75 & 10.6 & 0.24 & & & \\
\hline Differentiated & 35 & 11.3 & & & & \\
\hline \multicolumn{7}{|c|}{ Preoperative chemotherapy } \\
\hline Absence & 81 & 12.0 & 0.43 & & & \\
\hline Presence & 29 & 6.90 & & & & \\
\hline \multicolumn{7}{|c|}{ Postoperative chemotherapy } \\
\hline Absence & 27 & 5.97 & 0.003 & 2.00 & $1.10-3.52$ & 0.02 \\
\hline Presence & 83 & 11.9 & & & & \\
\hline \multicolumn{7}{|c|}{ Postoperative complication ${ }^{b}$} \\
\hline Presence & 22 & 6.13 & 0.11 & & & \\
\hline Absence & 88 & 10.7 & & & & \\
\hline \multicolumn{7}{|l|}{ Types of surgery } \\
\hline Bypass & 29 & 4.63 & 0.003 & 2.32 & $1.33-3.95$ & 0.003 \\
\hline Gastrectomy & 81 & 12.5 & & & & \\
\hline
\end{tabular}

aAccording to the Japanese Classification of Gastric Carcinoma 3rd edition; ${ }^{b}$ Grade 2 or higher according to the Clavien-Dindo classification; ${ }^{c}$ Values are from Log-rank test; ${ }^{\mathrm{d}} p$-Values are from Cox's proportional hazard model. M: Middle or lower third of stomach; U: upper third of stomach; cT: clinical T; cN: clinical N; OS: overall survival; HR: hazard ratio; CI: confidence interval.

( $p=0.003)$, and gastrojejunal bypass $(p=0.003)$ were identified as prognostic factors associated with worse outcomes by univariate analysis. Multivariate analysis using the Cox proportional hazard model revealed that age [Hazard Ratio $(\mathrm{HR})=1.93,95 \%$ Confidence Interval $(\mathrm{CI}): 1.15-3.22, p=0.01]$, clinical $\mathrm{N}$ stage $(\mathrm{HR}=1.80,95 \% \mathrm{CI}=1.04-3.26, p=0.03)$, postoperative chemotherapy $(\mathrm{HR}=2.00,95 \% \mathrm{CI}=1.10-3.52$, $p=0.02)$, and types of surgery $(\mathrm{HR}=2.32,95 \% \mathrm{CI}=1.33-3.95$, $p=0.003$ ) were independent prognostic factors.
Subgroup analysis of prognostic factors. A subgroup analysis of prognosis stratified by postoperative chemotherapy is shown in Figure 2. The 3-year OS of group G patients with postoperative chemotherapy was significantly better compared to group B patients ( $p=0.03$; Figure 2A). However, no difference was seen in the patients without postoperative chemotherapy (Figure 2B). On the other hand, with regard to the prognosis stratified by age greater than 70 years, gastrectomy significantly contributed to a better 


\section{Postoperative chemotherapy}

A

Presence: $n=83$

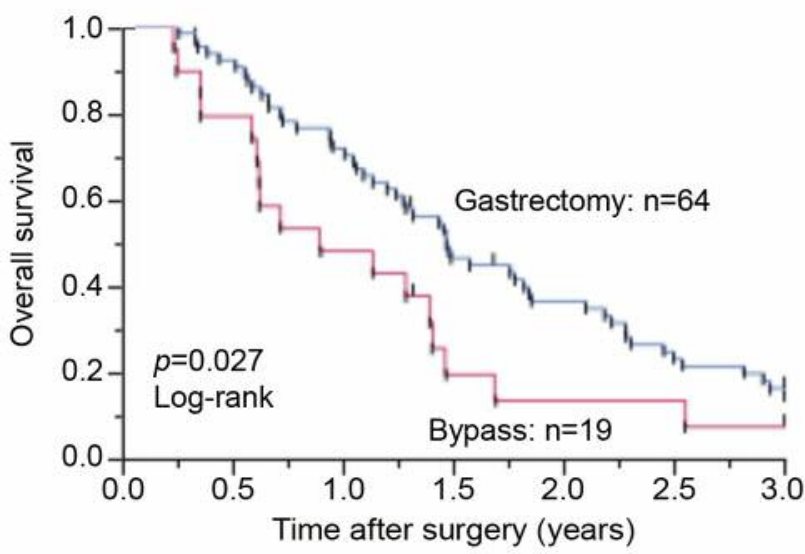

B

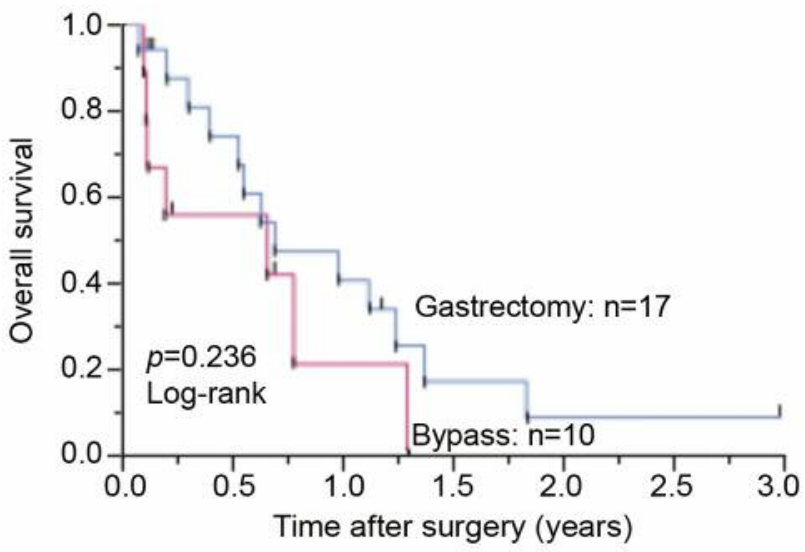

Age

C

Age, $<70: n=59$

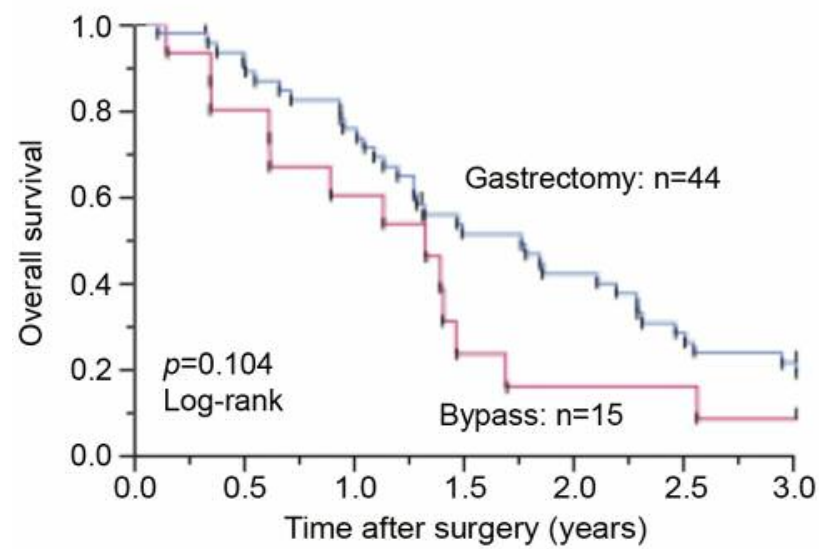

D

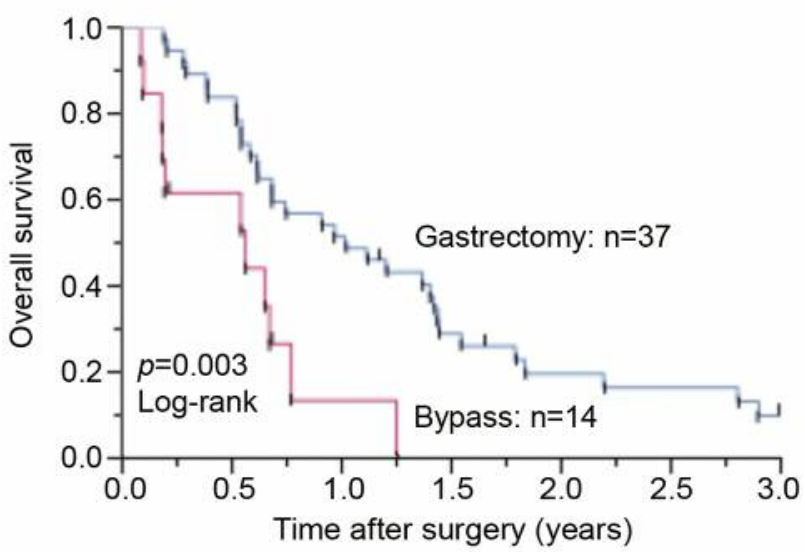

Figure 2. Subgroup analysis stratified by postoperative chemotherapy or age. (A, B) Overall survival using the Kaplan-Meier method is shown for patients with (A: $n=83)$ or without $(B: n=27)$ postoperative chemotherapy. $(C, D)$ Overall survival using the Kaplan-Meier method is shown for patients with age less than 70 years $(C: n=59)$ or more than 70 years $(D: n=51)$.

prognosis compared to gastrojejunal bypass $(p=0.003$; Figure $2 \mathrm{D})$. In patients younger than 70 years old, the difference was not significant ( $p=0.10$; Figure 2C).

Table IV shows the frequency of postoperative chemotherapy stratified by age and the types of surgery. In patients older than 70 years old, the frequency of postoperative chemotherapy was significantly lower compared to patients under $70(p<0.001)$, particularly in the group B compared to group $\mathrm{G}(43 \%$ versus $68 \%, p=0.11)$.

\section{Discussion}

The REGATTA trial has concluded that gastrectomy followed by chemotherapy does not show any survival benefits compared to chemotherapy alone in non-curable advanced gastric cancer (10). However, the REGATTA trial included only patients under 75 years of age with advanced gastric cancer and a single non-curable factor, and the patients received a single type of chemotherapy with $\mathrm{TS} 1+$ cisplatin. 
Table IV. Frequency of postoperative chemotherapy stratified by age and type of surgery.

\begin{tabular}{|c|c|c|c|c|c|c|}
\hline & $\begin{array}{l}\text { Postoperative } \\
\text { chemotherapy }\end{array}$ & $\begin{array}{c}\text { Bypass } \\
\mathrm{n}=29\end{array}$ & $\begin{array}{c}\text { Gastrectomy } \\
\mathrm{n}=81\end{array}$ & $p$-Value ${ }^{a}$ & $\begin{array}{c}\text { Total } \\
\mathrm{n}=110\end{array}$ & $p$-Value \\
\hline \multirow[t]{2}{*}{ Age: $<70$} & Presence & $13(87 \%)$ & $39(89 \%)$ & \multirow[t]{2}{*}{0.839} & $52(88 \%)$ & \multirow[t]{4}{*}{$<0.001$} \\
\hline & Absence & $2(13 \%)$ & $5(11 \%)$ & & $7(12 \%)$ & \\
\hline \multirow[t]{2}{*}{ Age: $\geq 70$} & Presence & $6(43 \%)$ & $25(68 \%)$ & \multirow[t]{2}{*}{0.107} & $31(61 \%)$ & \\
\hline & Absence & $8(57 \%)$ & $12(32 \%)$ & & $20(39 \%)$ & \\
\hline
\end{tabular}

${ }^{\mathrm{a}} \mathrm{p}$-Values are from Chi-squared test.

The impact of a variety of chemotherapeutic regimens or resection in elderly patients remains unclear. In this study, 28 patients (97\%) of Group B and 69 patients (86\%) of group G were not eligible for the REGATTA criteria, and among these patients Group $\mathrm{G}$ showed significantly better 3-year OS compared to Group B (12.6\% versus $4.85 \%, p=0.01)$.

In the present study, gastrectomy for patients with metastatic gastric cancer improved their survival compared to gastrojejunal bypass. The patients received various types of chemotherapies depending on their condition. A strong regimen is not suitable for every patient. Theoretically, gastrectomy may reduce the various symptoms or cytokines released by the primary tumor, thereby enhancing the systemic chemotherapy. It has also been shown that gastrectomy can reduce the number of tumor stem cells, possibly by increasing their sensitivity to palliative chemotherapy (15-18). These effects may possibly contribute to an improvement in the survival of patients following gastrectomy.

A subgroup analysis of prognosis stratified by postoperative chemotherapy has revealed that gastrectomy can imparted a survival benefit when combined with postoperative chemotherapy, whereas gastrectomy alone showed no survival benefit (Figure 2A and B). Moreover, in patients older than 70 years of age, the OS was better in group $\mathrm{G}$ compared to group $\mathrm{B}$ (Figure 2D). The low frequency of postoperative chemotherapy, particularly in elderly patients following gastrojejunal by-pass, may contribute to these results.

Univariate and multivariate analyses showed that postoperative chemotherapy, as well as gastrectomy were independent prognostic factors. We considered that chemotherapy is the standard of care for patients with metastatic gastric cancer. The main roles of palliative gastrectomy are to relieve cancer-related symptoms and to enhance the efficacy of chemotherapy, but not to cure the disease. Therefore, it is reasonable that gastrectomy itself has no survival benefit if not followed by postoperative chemotherapy and these results are consistent with other reports $(19,20)$.

In the present study, the frequency of postoperative complications of grade 2 or higher in group G was $22 \%$ (18/81), whereas the previously reported morbidity rate following palliative gastrectomy in patients with metastatic gastric cancer ranged from 10.4 to $26 \%$ (19-21). There was no significant difference in the frequency of postoperative complications between groups $\mathrm{G}$ and $\mathrm{B}$. Therefore, although the lengths of the hospital stays were longer in group $\mathrm{G}$, we consider that our surgical outcomes are comparable to those of other reports (1921 ), and that palliative gastrectomy for patients with metastatic gastric cancer is a safe and feasible treatment.

There were some limitations in this study. The sample size was too small, particularly for group B, to explore the role of the surgical strategy. In addition, presumably there were some selection and therapeutic biases due to the retrospective nature of the study. Moreover, due to the long-term patient registration and the lack of a standard treatment strategy for metastatic gastric cancer, there may have been inconsistencies regarding the postoperative chemotherapy regimen or indication for the types of surgery that should be followed. Most of therapeutic strategies were decided on a case-by-case basis.

In conclusion, although the present study was performed using limited case samples and has some inherent biases, it suggests that gastrectomy followed by postoperative chemotherapy in patients with metastatic gastric cancer may improve their survival compared to the gastrojejunal bypass. Further studies are needed to evaluate postoperative chemotherapy and its therapeutic effects in elderly patients.

\section{Authors' Contributions}

Matsubara D and Konishi $\mathrm{H}$ contributed equally to this study; Matsubara D, Konishi $\mathrm{H}$ and Otsuji $\mathrm{E}$ designed the research; Konishi H, Kosuga T, Kubota T and Okamoto K treated the patients and collected the data; Matsubara D and Konishi $\mathrm{H}$ analyzed the data; Matsubara D, Konishi H and Otsuji E wrote the manuscript.

\section{References}

1 Ferlay J, Soerjomataram I, Dikshit R, Eser S, Mathers C, Rebelo M, Parkin DM, Forman D and Bray F: Cancer incidence and mortality worldwide: sources, methods and major patterns in GLOBOCAN 2012. Int J Cancer 136: E359-386, 2015. PMID: 25220842. DOI: $10.1002 / \mathrm{ijc} .29210$

2 Park SC and Chun HJ: Chemotherapy for advanced gastric cancer: review and update of current practices. Gut Liv 7(4): 385-393, 2013. PMID: 23898376. DOI: 10.5009/ gnl.2013. 7.4.385 
3 Wagner AD, Syn NL, Moehler M, Grothe W, Yong WP, Tai BC, Ho $J$ and Unverzagt $S$ : Chemotherapy for advanced gastric cancer. Cochrane Database Syst Rev 8: CD004064, 2017. PMID: 28850174. DOI: 10.1002/14651858.CD004064.pub4

4 Japanese Gastric Cancer Association: Japanese gastric cancer treatment guidelines 2014 (ver. 4). Gastric Cancer 20(1): 1-19, 2017. PMID: 27342689. DOI: 10.1007/s10120-016-0622-4

5 Ebinger SM, Warschkow R, Tarantino I, Schmied BM, Güller U and Schiesser M: Modest overall survival improvements from 1998 to 2009 in metastatic gastric cancer patients: a populationbased SEER analysis. Gastric Cancer (3): 723-734, 2016. PMID: 26391158. DOI: 10.1007/s10120-015-0541-9

6 Chang YR, Han DS, Kong SH, Lee HJ, Kim SH, Kim WH and Yang HK: The value of palliative gastrectomy in gastric cancer with distant metastasis. Ann Surg Oncol 19(4): 1231-129, 2012. PMID: 22045464. DOI: 10.1245/s10434-011-2056-x

7 Lasithiotakis K, Antoniou SA, Antoniou GA, Kaklamanos I and Zoras O: Gastrectomy for stage iv gastric cancer. a systematic review and meta-analysis. Anticancer Res 34(5): 2079-2085, 2014. PMID: 24778009.

8 Ouchi K, Sugawara T, Ono H, Fujiya T, Kamiyama Y, Kakugawa $\mathrm{Y}$, Mikuni $\mathrm{J}$ and Yamanami $\mathrm{H}$ : Therapeutic significance of palliative operations for gastric cancer for survival and quality of life. J Surg Oncol 69(1): 41-44, 1998. PMID: 9762890.

9 Gold JS, Jaques DP, Bentrem DJ, Shah MA, Tang LH, Brennan MF and Coit DG: Outcome of patients with known metastatic gastric cancer undergoing resection with therapeutic intent. Ann Surg Oncol 14(2): 365-372, 2007. PMID: 17146744. DOI: 10.1245/s10434-006-9059-z

10 Fujitani K, Yang HK, Mizusawa J, Kim YW, Terashima M, Han SU, Iwasaki Y, Hyung WJ, Takagane A, Park DJ, Yoshikawa T, Hahn S, Nakamura K, Park CH, Kurokawa Y, Bang YJ, Park BJ, Sasako M, Tsujinaka $\mathrm{T}$ and REGATTA study investigators: Gastrectomy plus chemotherapy versus chemotherapy alone for advanced gastric cancer with a single non-curable factor (REGATTA): A phase 3, randomised controlled trial. Lancet Oncol 17(3): 309-318, 2016. PMID: 26822397. DOI: 10.1016/ S1470-2045(15)00553-7

11 Japanese Gastric Cancer Association: Japanese classification of gastric carcinoma: 3rd English edition. Gastric Cancer 14: 101112, 2011. PMID: 11957040. DOI: 10.1007/s101209800016

12 Dindo D, Demartines N and Clavien PA: Classification of surgical complications: a new proposal with evaluation in a cohort of 6336 patients and results of a survey. Ann Surg 240: 205-213, 2004. PMID: 15273542.
13 Clavien PA, Barkun J, de Oliveira ML, Vauthey JN, Dindo D, Schulick RD, de Santibañes E, Pekolj J, Slankamenac K, Bassi C, Graf R, Vonlanthen R, Padbury R, Cameron JL and Makuuchi M: The Clavien-Dindo classification of surgical complications: five-year experience. Ann Surg 250: 187-196, 2009. PMID: 19638912. DOI: 10.1097/SLA.0b013e3181b13ca2

14 Gandevia B and Tovell A: Declaration of Helsinki. Med J Aust 2: 320-321, 1964. PMID: 14194486.

15 Visvader JE and Linderman GJ: Cancer stem cells in solid tumours: Accumulating evidence and unresolved questions. Nat Rev Cancer 8(10): 755-768, 2008. PMID: 18784658. DOI: 10.1038/nrc2499

16 Clarke MF, Dick JE, Dirks PB, Eaves CJ, Jamieson CH, Jones DL, Visvader J, Weissman IL and Wahl GM: Cancer stem cells-perspectives on current status and future directions: AACR Workshop on cancer stem cells. Cancer Res 66(19): 9339-9344, 2006. PMID: 16990346. DOI: 10.1158/0008-5472.CAN-06-3126

17 Dean M, Fojo T and Bates S: Tumour stem cells and drug resistance. Nat Rev Cancer 5: 275-284, 2005. PMID: 15803154. DOI: $10.1038 / \mathrm{nrc} 1590$

18 Lippitz BE: Cytokine patterns in patients with cancer: a systematic review. Lancet Oncol 14(6): e218-e228, 2013. PMID: 23639322. DOI: 10.1016/S1470-2045(12)70582-X

19 Nie RC, Chen S, Yuan SQ, Chen XJ, Chen YM, Zhu BY, Qiu HB, Peng JS and Chen YB: Significant role of palliative gastrectomy in selective gastric cancer patients with peritoneal dissemination: a propensity score matching analysis. Ann Surg Oncol 23(12): 3956-3963, 2016. PMID: 27380641. DOI: 10.1245/s10434-016-5223-2

20 Yang K, Liu K, Zhang WH, Lu ZH, Chen XZ, Chen XL, Zhou $\mathrm{ZG}$ and $\mathrm{Hu} \mathrm{JK}$ : The value of palliative gastrectomy for gastric cancer patients with intraoperatively proven peritoneal seeding. Medicine 94(27): e1051, 2015. PMID: 26166075. DOI: 10.1097/ MD.0000000000001051

21 Medina-Franco H, Contreras-Saldívar A, Ramos-De La Medina A, Palacios-Sanchez P, Cortés-González R and Ugarte JA: Surgery for stage IV gastric cancer. Am J Surg 187(4): 543-546, 2004. PMID: 15041508. DOI: 10.1016/j.amjsurg.2003.12.045

Received March 24, 2019 Revised April 14, 2019 Accepted April 17, 2019 